\title{
Editorial
}

\section{Patient education for the management of disease}

\section{Jean Bosco Gahutu}

\section{Editor in Chief}

Effective management of disease depends not only on good diagnosis and judicious treatment but also on patienthealthcare provider interaction, in particular patient education.

While patient education for hospitalized patients can be structured, education of outpatients presents organizational challenges, especially for patients suffering from non-communicable diseases, e.g. diabetes mellitus.

Youth camps are gaining interest as educational method. Education is an important component of diabetes management at camps for children with diabetes mellitus.[1] Youth camps are particularly useful as they offer optimal lifestyle conditions, including healthy diet and exercise.

To maximize the benefits of camps for children living with diabetes mellitus, educational goals are set beforehand and a checklist is used to evaluate to which extent the learning outcomes are achieved.[2]

An article reporting educational camps for youth living with type 1 diabetes mellitus is published in this issue. This study confirms previous findings on the usefulness of educational camps in the control of type 1 diabetes mellitus for children in sub-Saharan Africa.[3]

Researchers should explore how such educational camps can be used for other types of non-communicable diseases.

\section{References}

1. Wendt LFC. Diabetes management at camps for children with diabetes. Diabetes Care. 2012;35.

2. Nabors LA, Kichler JC, Burbage ML, Swoboda CM, Andreone TL. Children's learning and goal-setting at a diabetes camp. Diabetes Spectr. 2014;27:257-63.

3. Dehayem MY, Takogue R, Choukem SP, Donfack OTS, Katte JC, Sap S, et al. Impact of a pioneer diabetes camp experience on glycemic control among children and adolescents living with type 1 diabetes in sub-Saharan Africa. BMC Endocr Disord [nternet]. BMC Endocrine Disorders; 2016;16:10-5. Available from: http://dx.doi. org/10.1186/s12902-016-0086-x 